\title{
Effect of thermoplastic morphology on mechanical properties in laser-assisted joining of polyamide 6 with aluminum
}

\author{
Klaus Schricker $^{1}$ (D) Jean Pierre Bergmann ${ }^{1} \cdot$ Marcus Hopfeld $^{2} \cdot$ Lothar Spieß $^{2}$
}

Received: 11 June 2020 / Accepted: 3 December 2020 / Published online: 18 December 2020

(C) The Author(s) 2020

\begin{abstract}
This paper examined the joining zone between semi-crystalline polyamide 6 and aluminum EN AW 6082 in laser-based joining and evaluated the mechanical properties of the joint. The joint tests were carried out in overlap configuration and a characterized in terms of energy per unit length. The mechanical properties were examined to the point of cohesive failure. An increasing energy per unit length resulted in a reduced crosshead displacement in short-term testing and a decreased fatigue strength. Further material testing was carried out locally at various positions within the joining zone. The mechanical properties were correlated with results of a hardness test, thermoplastic morphology, differential scanning calorimetry (DSC), and X-ray diffraction (XRD). By combining the findings with heat-treated samples at elevated temperatures, secondary crystallization was identified and evidenced as a primary effect among the changes in mechanical properties due to the heat treatment of the thermoplastic material.
\end{abstract}

Keywords Laser welding $\cdot$ Hybrid welding $\cdot$ Dissimilar materials $\cdot$ Plastics $\cdot$ Microstructure

\section{Introduction}

Metal-polymer hybrids are gaining importance due to the continuing demand for lightweight design, integration of functions, and cost reduction. Aluminum and polymetric materials ranging from thermosets to thermoplastics are widely used in different fields and applications, especially in automotive and aviation sector. Large-scale production is mainly based on

Recommended for publication by Commission XVI - Polymer Joining and Adhesive Technology

Klaus Schricker

klaus.schricker@tu-ilmenau.de

Jean Pierre Bergmann

jeanpierre.bergmann@tu-ilmenau.de

Marcus Hopfeld

markus.hopfeld@tu-ilmenau.de

Lothar Spieß

lothar.spiess@tu-ilmenau.de

1 Production Technology Group, Technische Universität Ilmenau, Gustav-Kirchhoff-Platz 2, 98693 Ilmenau, Germany

2 Materials for Electronics Group, Technische Universität Ilmenau, Gustav-Kirchhoff-Strasse 5, 98693 Ilmenau, Germany thermoplastics due to a higher level of automation and short cycle times.

The use of thermoplastic materials is advantageous for manufacturing hybrid joints. The use of thermoplastics eliminates the need for adhesives or joining elements such as screws and rivets because the materials can be directly connected through thermal joining processes. Thermal joining can be performed by different energy sources, e.g., ultrasonic joining [1], induction joining [2], or laser joining [3]. The use of laser irradiation has advantages over alternative processes due to high flexibility, non-contact energy input, and the potential to adapt intensity distributions to achieve materialspecific temperature-time profiles.

The laser-based joining process is mostly carried out as heat conduction joining [4]. This means that the laser beam is absorbed in the metal surface, then the heat is conducted through the metal sheet and transferred into the thermoplastic at the boundary layer. An area of molten material is formed in the polymer that penetrates the surface structures and wets the metal surface. A solid joint is formed after solidification.

Both the formation of the molten area and its thickness depend on the energy input, the metal sheet thickness, and the material properties, particularly the melting interval [5]. A simplified description based on a numerical study of the molten area is given in [6], although the melting interval was not considered and was later identified as a key parameter 
[7]. More detailed studies focussed on the correlation between the temperature distribution and the thermoplastic morphology [8]. Different areas within the morphology were identified, e.g., fully molten zones, partially molten zones, and a deformation of spherulites $[6,8,9]$. Furthermore, a change in crystal modification was demonstrated for a polyamide 6aluminum joint [8]. Further studies were carried out regarding the change in degree of crystallinity that is or may be influenced by the time-temperature profile or the process [10-12].

Beyond the thermal joining of metals with polymers, it has been shown that the processing of polymers has a decisive influence on the mechanical properties. Trials on hot gas welding and hot plate welding showed effects on weld strength based on the thickness of a recrystallized zone, deformed spherulites, or stretched spherulites [13-15]. In contrast, [16] examined a correlation between decreasing spherulite size and increasing tensile strength. The effect of spherulitic structures was subordinated to crystal lamellae in further studies [17]. Furthermore, a change of superstructures can also influence the deformation behavior of amorphous regions between spherulites and deformation of spherulites themselves $[18,19]$, which is why no generally valid description has yet been given of the effect of superstructures.

Further studies were performed to describe different crystal structures and their effect on the properties of polymers. Isolated trials were carried out in most cases to determine different crystal modifications and their effect on material properties, e.g., for polyamide $6[20,21]$. The $\alpha$ - and $\gamma$ phases are the relevant crystal modifications of polyamide 6 , in which their properties differ significantly in Young's modulus, density, or melting interval [21-23]. The resulting crystal modification is influenced by the temperature during crystallization and the cooling rate in particular [20, 24]. For example, a decelerated cooling rate leads to increased formation of the $\alpha$-phase compared to the $\gamma$-phase [25]. Furthermore, the $\gamma$-modification is not thermally stable and can be converted into $\alpha$-polyamide 6 by heat treatment $[20,25]$. The joining process influences these properties by the process conditions especially due to the temperature-time profile.

Such effects are not taken into account by the studies on the mechanical properties of plastic-metal joints. Most studies focus on mechanical properties and the effect of variable such as stress distribution, deformation and stiffness [26], bubble formation [27], oxide layers [28], and base material strength [29, 30]. Overall, adhesive fracture, cohesive fracture, and mixed fracture were identified as possible fracture patterns [30]. The cohesive fracture of the weaker joining partner was in general the preferred fracture pattern for multi-material composites in industrial applications since the failure location can be clearly determined [31]. Further studies on metal-polymer joints indicated at least an influence of the joining process on the cohesive failure of thermally joined metal-plastic components. [9] showed that the crosshead displacement in tensile-shear testing increases with rising joining speed for polyamide 6.6-aluminum joints. However, a correlation between these effects on material science of thermally joined metalpolymer composites has not yet been given.

In this paper, thermally joined polyamide 6-aluminum composites are examined in order to determine the key factors for influencing the mechanical properties based on a variable energy per unit length. The cohesive failure of the polyamide 6 was the focus of the study because of its relevance to industrial requirements. The effects were demonstrated in shortterm and fatigue testing and traced back to the distinct changes in material properties.

\section{Materials and methods}

The experimental setup is shown in Fig. 1a. A diode laser (Laserline, LDM 3000, focal diameter: $5.3 \mathrm{~mm}$, average wavelength: $980 \mathrm{~nm}$ ) was used for the joining process. The clamping device allowed a precise adjustment of clamping pressure by load cells and was set to $0.1 \mathrm{~N} \mathrm{~mm}^{-2}$. The distance between the clamping jaws was $12 \mathrm{~mm}$. The joining process was carried out with a constant laser beam power of $1 \mathrm{~kW}$. The energy per unit length was varied in steps of $50 \mathrm{~kJ} \mathrm{~m}^{-1}$ by adjusting the welding speed $v_{\mathrm{w}}$. While melting of the metallic joining partner was avoided in order to enable the composite to be used in the visible area, the overall width of the overlap had to be connected. This allowed the process window to be limited to a range of energy per unit length from 200 to $400 \mathrm{~kJ}$ $\mathrm{m}^{-1}$ (Fig. 1b).

Aluminum (EN AW 6082 T6) and polyamide 6 (natural material without additional additives) were chosen as materials with a typical material thickness due to their use in various applications. The metallic joining partner had a material thickness of $1.5 \mathrm{~mm}$ and the thermoplastic joining partner 2 $\mathrm{mm}$. The length and width of the specimens were set to $300 \mathrm{~mm}$ and $75 \mathrm{~mm}$. The metal surface was pre-treated with a fiber laser (Rofin PowerLine F20) that was used to cut linear grooves (Fig. 2a). This pulsed laser process provides relatively uniform surface structures with undercuts (Fig. 2b). The joint configuration in the overlap joint is shown in Fig. 2c. An overlap of $16 \mathrm{~mm}$ between the two materials was selected. The overlap width was based on typical applications in automotive applications.

Materialographic specimens were prepared by ion etching (Gatan Precision Etching Coating System Model 682, power: $4 \mathrm{keV}$, rotational speed: $30 \mathrm{~min}^{-1}$, tilting angle: $0-60^{\circ}$, tilting speed: $15 \mathrm{~min}^{-1}$, duration: $40 \mathrm{~min}$ ) and examined using differential interference contrast microscopy (DIC, Zeiss Axio Imager.M2m). A further characterization of the joining zone was carried out using X-ray diffraction (XRD, Bruker Lynxeye XE-T, spot size: $300 \mu \mathrm{m}$, measurement time per step: $60 \mathrm{~s}$, diffraction angle: $7.5^{\circ} \ldots 62^{\circ}$ ) and thermal analysis 
Fig. 1 Experimental setup (a) and joint configuration (b)

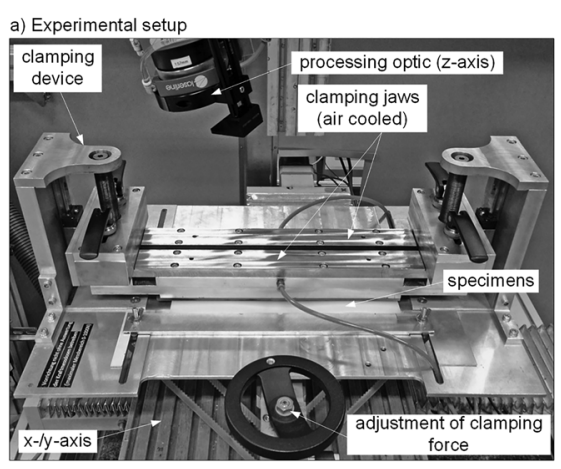

by differential scanning calorimetry (DSC, Netzsch DSC 204 F1 Phoenix, heating rate: $10 \mathrm{~K} \mathrm{~min}^{-1}$ ). For the thermal analysis, thin sections with a thickness of $50 \mu \mathrm{m}$ (length: $2 \mathrm{~mm}$, width: $2 \mathrm{~mm}$ ) were cut out of the joining zone. Temperature measurement was carried out by thermocouples type $\mathrm{K}$ in the middle of the joining zone (Dewetron Dewe 5000, diameter: $0.2 \mathrm{~mm}$, recording rate: $100 \mathrm{~Hz}$ ). All measuring positions are illustrated in each figure.

The mechanical testing was performed on tensile-shear samples (width: $50 \mathrm{~mm}$, free clamping length: $30 \mathrm{~mm}$, Fig. 2c). Short-term testing was carried out on a universal testing machine (Hegewald \& Peschke Inspekt $145520 \mathrm{kN}$ ) with test speed of $250 \mathrm{~mm} \mathrm{~min}^{-1}$. This relatively high test speed was chosen to limit the influence of the base material on the test result [9]. The fatigue test was performed on a high-frequency pulsator (SincoTec Power Swing Mot) at resonant frequency. The sample preparation and free clamping length were the same for the fatigue test as for the short-term tensile-shear test. For the fatigue test, a stress ratio $\mathrm{R}=0.1$ was determined under cyclic tensile-shear load and performed for up to $10^{7} \mathrm{load}$ cycles to verify the fatigue strength. A change of $\pm 3 \mathrm{~Hz}$ in the resonant frequency, which indicated the presence of a crack, was applied as a shut-down criterion. The nominal

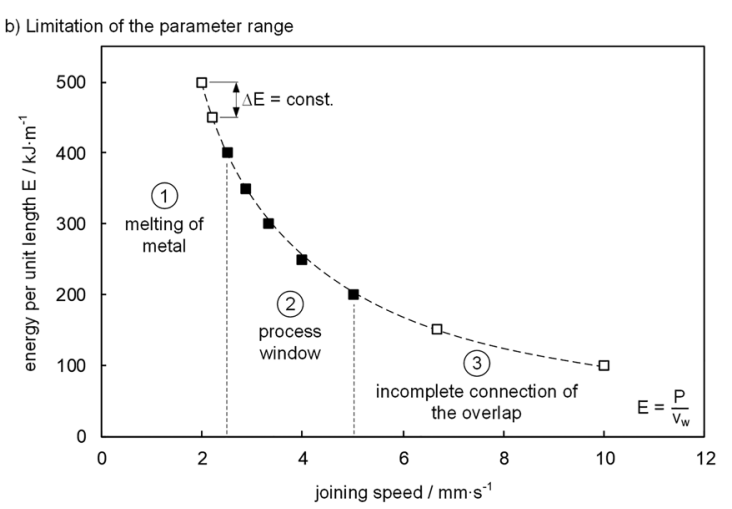

loads used were $2.1 \mathrm{kN}$ as maximum and $0.21 \mathrm{kN}$ as minimum in order to be able to compare different energies per unit length based on an identical aggregate load. The actual loads and the frequency were recorded as a function of the load cycles during the test. A period of at least seven days after manufacturing was allowed to elapse before mechanical testing of the metal-polymer joints. This was done to allow the reabsorption of water from the ambient atmosphere. Microsections of the mechanically tested samples were taken at the sample center.

\section{Results and discussion}

\subsection{Joining zone and molten area}

The experiments were designed to vary energy per unit length in the range from 200 to $400 \mathrm{~kJ} \mathrm{~m}^{-1}$. No further experiments beyond this range were carried out because the polymer was not connected over the entire overlap width at lower unit energies and the metal joining partner was molten at higher unit energies (see Section 2).
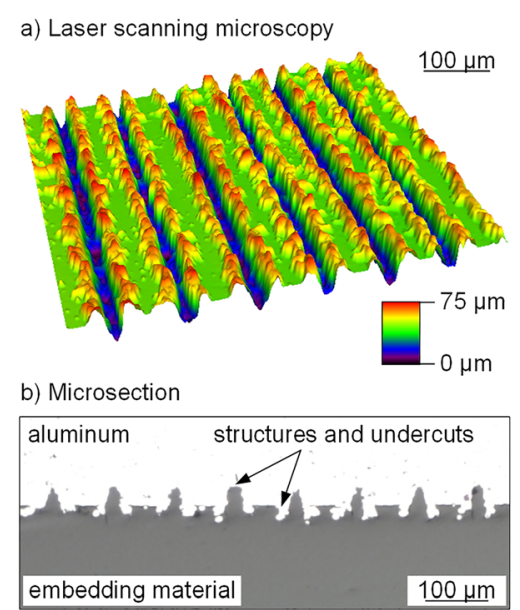

c) Joint configuration

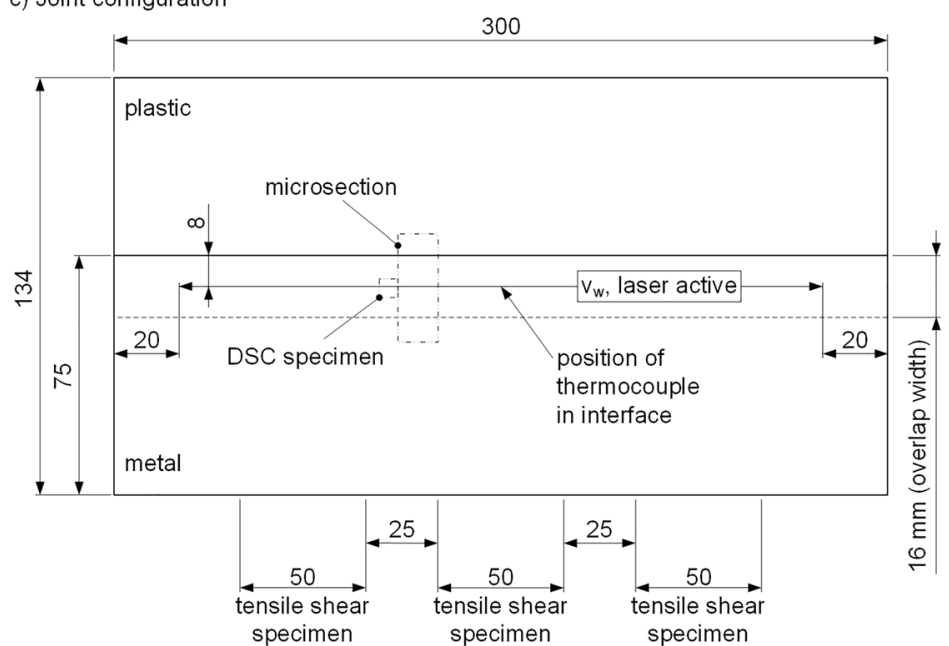

Fig. 2 Fiber laser surface pre-treatment of aluminum (a, b) and joint configuration (c) 
Figure 3 compares the joining zone based on the minimum and maximum energy per unit length of 200 and $400 \mathrm{~kJ} \mathrm{~m}^{-1}$. In both cases, the molten area in the polymer extends over the entire overlap width, $16 \mathrm{~mm}$. Starting from the sheet edge, a width of $14 \mathrm{~mm}$ was structured before the joining process. This procedure ensured that all surface structures within the overlap were completely filled with polymer. In addition, the occurrence of notches due to unfilled structures outside the joining zone that could adversely affect the mechanical properties of the hybrid component was prevented. The ejected melt occurring at the edge of the overlap was due to the increase in volume in the phase transition and the joining pressure. With increasing energy per unit length, more material is molten and a significantly larger flash forms at the edge of the overlap. Bubbles occurred sporadically in the molten area for both line energies; these were partly transported in the direction of the flash during the joining process. The surface structures within the joining zone were completely filled with polymer, even below the bubbles. Following [32], it is assumed that the bubbles separated from the interface during cooling, since there is a gap filled with polymer between the bubble and the interface.

The maximum thickness of the molten area was located in the middle of the overlap and decreased to the left and right.
Heat accumulated at the edge of the polymer towards the metal, which is why the thickness of the molten area increased again at this point. The expansion of the molten zone nearly doubled from approximately $320 \mu \mathrm{m}$ at $200 \mathrm{~kJ} \mathrm{~m}^{-1}$ to $630 \mu \mathrm{m}$ at $400 \mathrm{~kJ} \mathrm{~m}^{-1}$ over the range of energies per unit length considered. At the same time, the metal penetrates deeper into the thermoplastic joining partner with increasing energy per unit length, resulting in a reduction of the thermoplastic crosssection by approximately $5 \%$.

A more detailed view of the molten area thickness is given in Fig. 4. The graph increased nearly linearly in the examined interval of energies per unit length which is a significant difference compared to the exponential growth of the molten area in spot joints [8]. Based on the superposition of heat conduction with heat accumulation and melt ejection, the molten area thickness increased linearly in the considered interval with increasing energy per unit length. A coefficient of determination of 0.99 was achieved for linear interpolation. The standard deviation was at maximum $\pm 11.3 \mu \mathrm{m}$ which was equal to $\pm 2.7 \%$. This illustrates that it was possible to carry out the joining process in a highly reproducible manner.

A change in energy per unit length caused not only molten areas of different sizes but also modifications in the joining partners, especially in the thermoplastic material.

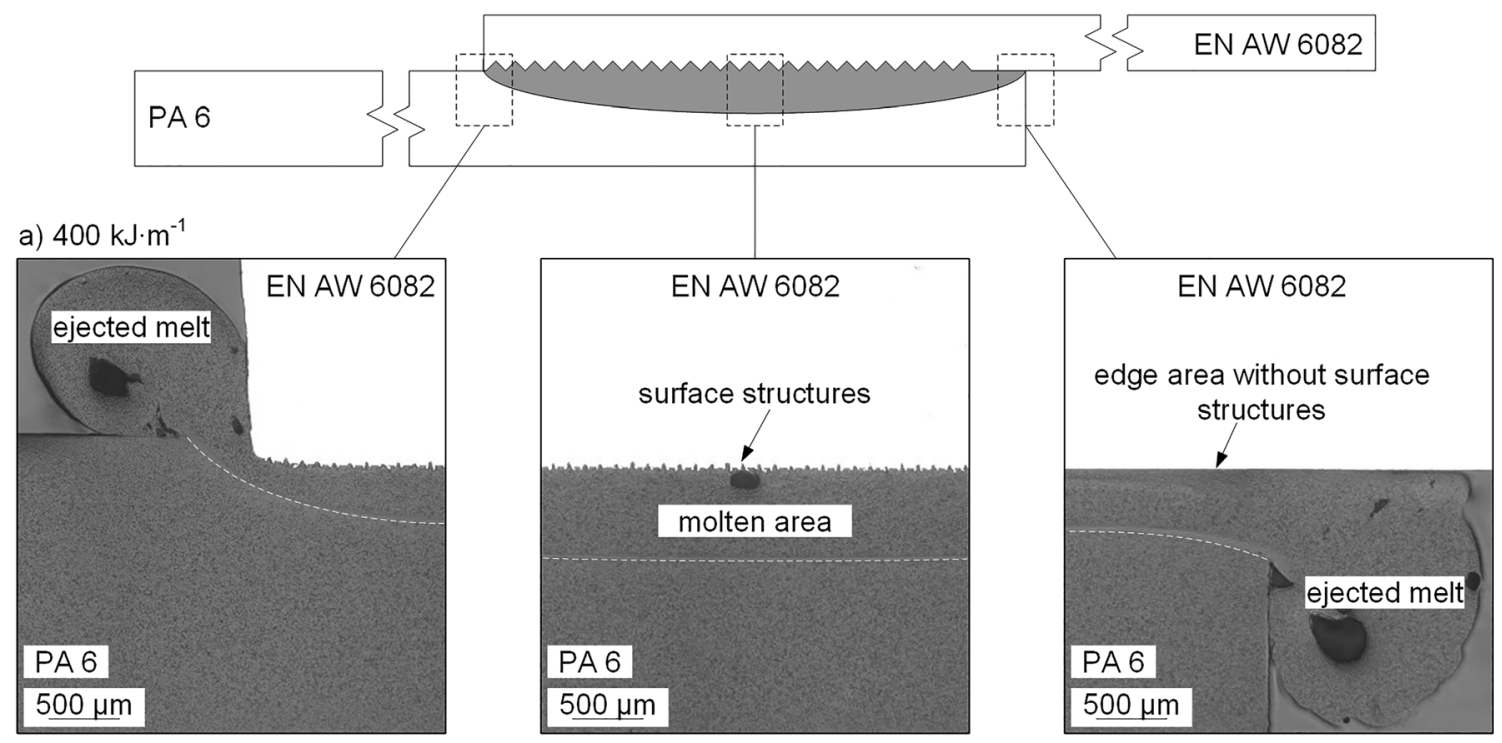

b) $200 \mathrm{~kJ} \cdot \mathrm{m}^{-1}$
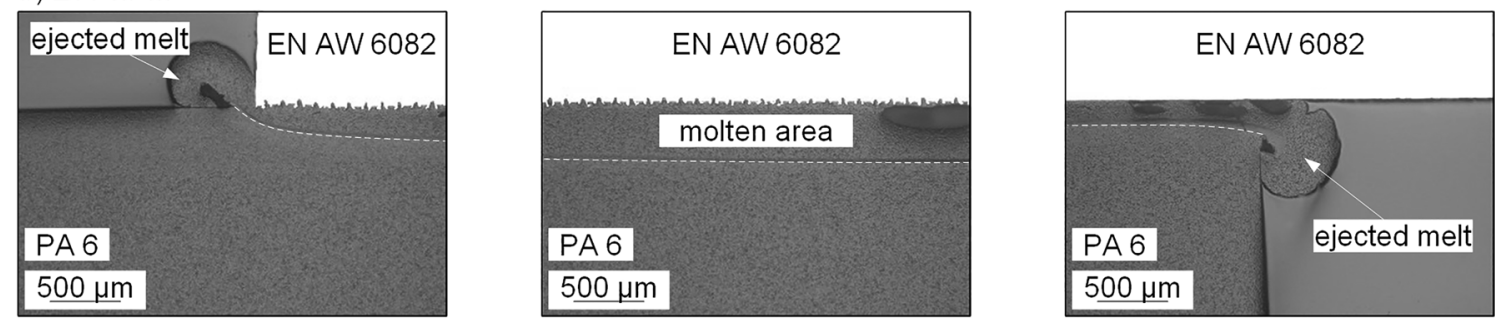

Fig. 3 Appearance of molten area for different energies per unit length $\mathbf{a} 400 \mathrm{~kJ} \mathrm{~m}^{-\mathbf{1}}$ and $\mathbf{b} 200 \mathrm{~kJ} \mathrm{~m}^{-1}$ 
Fig. 4 Thickness of molten area depending on energy per unit length

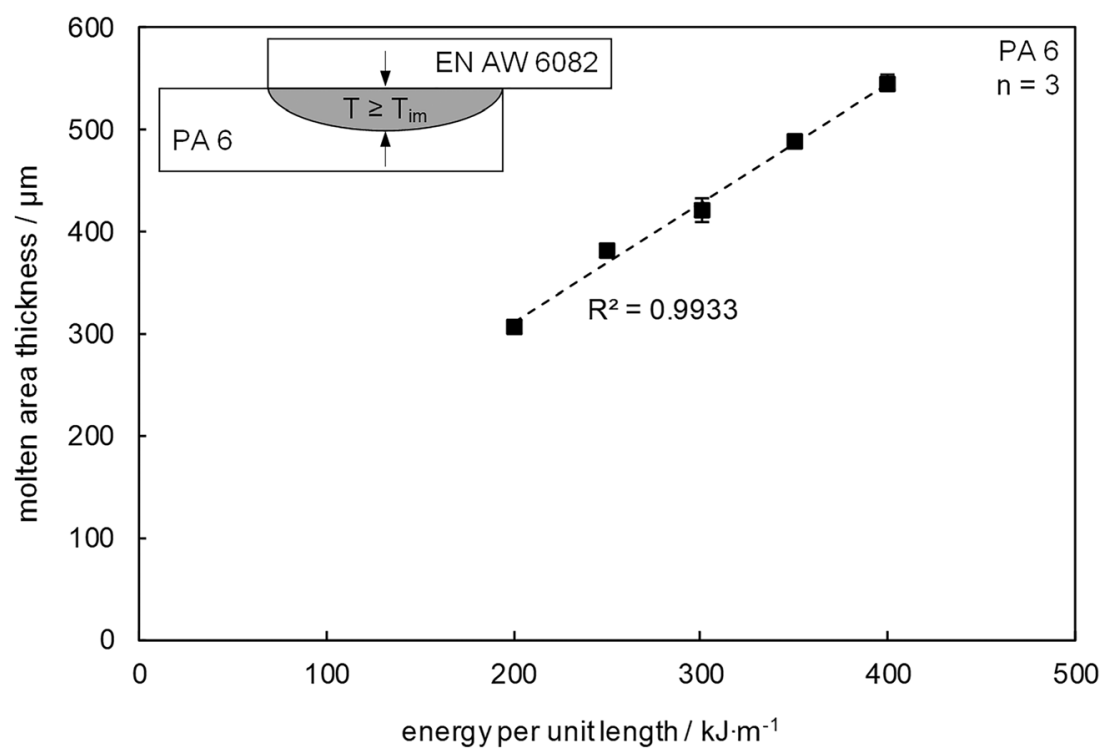

\subsection{Thermoplastic morphology and modification of properties due to thermal joining}

The modification of material properties in the joining process was considered for different energies per unit length. Due to the temperatures, dwell times, and heating rates that occur in aluminum, a heat-affected zone was formed as described in detail in [8]. However, this heat-affected zone did not have a significant influence on the mechanical properties of the hybrid component based on the cohesive failure of the nonreinforced polymer; i.e. the composite failed under mechanical load in the thermoplastic joining partner. For this reason, a more detailed examination of the heat-affected zone in aluminum was omitted. The properties of the plastic were decisive at this point.

Figure 5 a illustrates the characteristic morphology using two positions for a composite of PA 6 with EN AW 6082. Two zones can be seen in the edge area of the overlap: (a) a zone with deformed spherulites caused by the flow of melt and (b) a fine spherulitic zone towards the base material caused by the influence of the functional groups on crystallization and nucleation. Bubbles were found a few micrometers above the interface as described in Section 3.1. These areas of the thermoplastic morphology were comparable with the trials on spot joints $[6,8]$. A more detailed examination of the boundary surface in Fig. 5b showed that the spherulites were relatively uniform. This applied even within the surface structures; i.e., no amorphous layer was detected. This can be explained by the slow solidification of the polymer due to the indirect joining process since the heated metal delayed the cooling process.

A qualitative comparison of spherulite sizes depending on energy per unit length was challenging; however, a slight coarsening of the superstructures between 200 and $400 \mathrm{~kJ}$ $\mathrm{m}^{-1}$ can be discussed. The larger superstructures can be traced back to an increased maximum temperature with rising energy per unit length and delayed cooling. This provided a longer time interval for the formation of spherulites during solidification for the polymer and reduced the nucleation rate. However, it should be noted that it was difficult to determine structure sizes. The ablation of the amorphous areas exposed the crystalline structures; i.e., effects such as secondary crystallization can also influence optical appearance.

The temperature-time profile changed significantly for different energies per unit length. Figure 6 shows the timetemperature curve in the middle of the joining zone for minimum and maximum energy per unit length. The temperature curves were referenced to a time $t=0$ for better comparability; this does not however represent the start of the process, but when the temperature fell below crystallization temperature $T_{\mathrm{pc}}$ during cooling. At the process start, the laser beam started moving and passed the measuring point at the interface at half the seam length. The maximum temperature was reached at this time and rose at the same time as the energy per unit length increases. A temperature of approx. $490{ }^{\circ} \mathrm{C}$ was reached for an energy per unit length of $400 \mathrm{~kJ} \mathrm{~m}^{-1}$, whereas $375{ }^{\circ} \mathrm{C}$ was not exceeded for $200 \mathrm{~kJ} \mathrm{~m}^{-1}$. Despite exceeding the decomposition temperature for $400 \mathrm{~kJ} \mathrm{~m}^{-1}$, a further increase of bubble formation was expected; however, only some isolated bubbles within joining zone were detected. The limited amount of bubbles is explained by (a) degassing of bubbles at the interface (see [32]) and (b) the transport of bubbles as a result of melt ejection due to the limited overlap width. The temperature decreased after the laser beam focus passed the thermocouple and reached ambient temperature after the laser beam was switched off.

A comparison of solidification times in the crystallization interval (191-153 ${ }^{\circ} \mathrm{C}$, determined for a heating rate of $-10 \mathrm{~K}$ 
a) Thermoplastic morphology

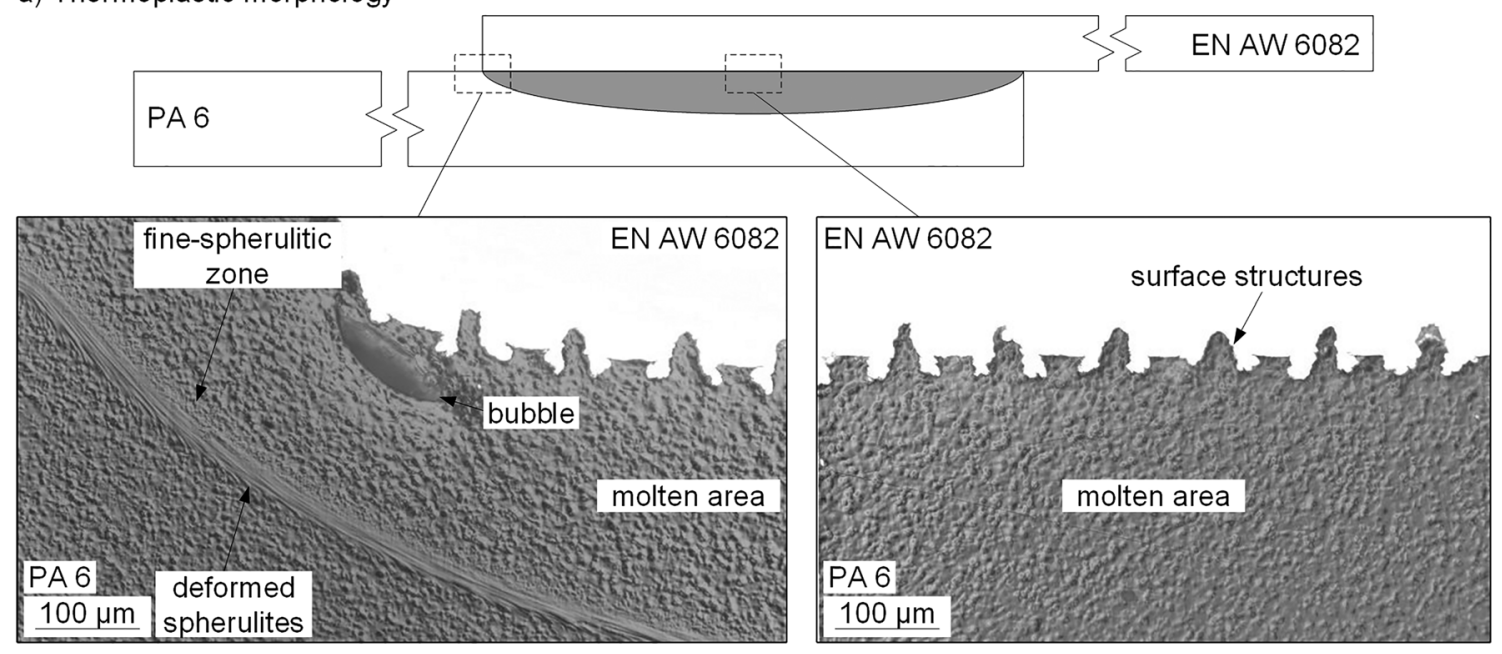

b) Effect of energy per unit length on thermoplastic morpholgy
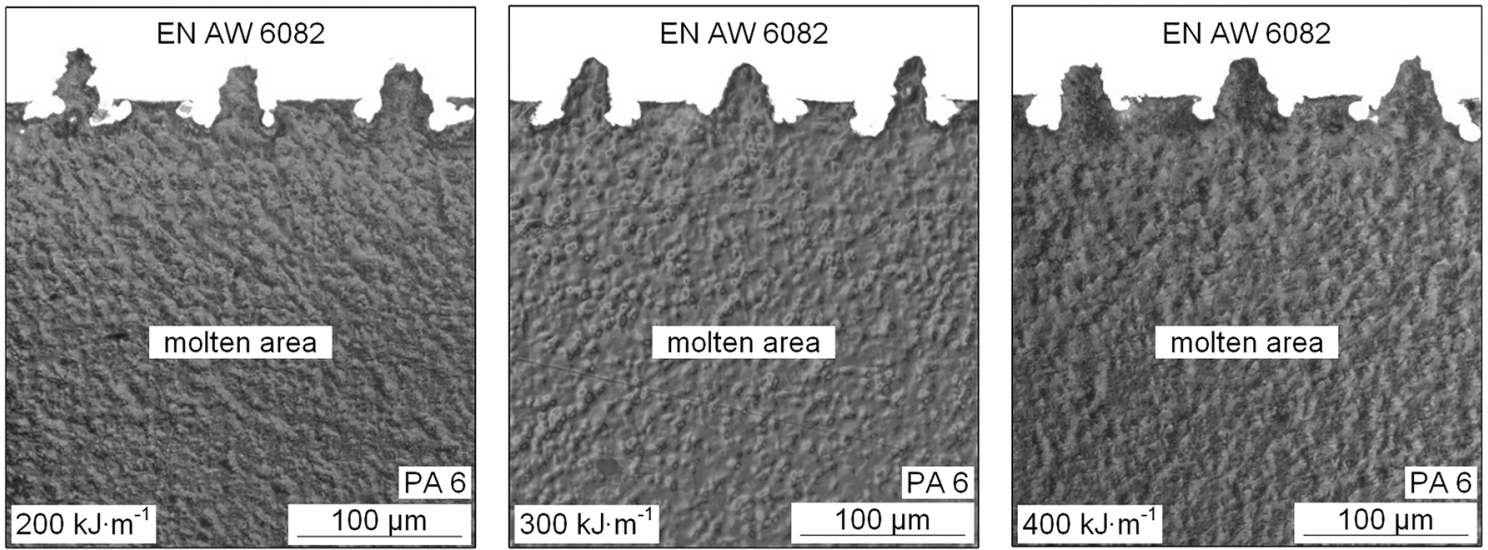

Fig. 5 a Thermoplastic morphology of the molten area and $\mathbf{b}$ effect of different energies per unit length

$\min ^{-1}$ ) led to the conclusion that more time can be available for solidification with increasing energy per unit length. This was also indicated by a tendency towards coarsening of existing spherulitic superstructures (Fig. 5). It should be noted that a precise determination of these time intervals was not appropriate at this point due to the large temperature dependence of the crystallization interval on cooling rate, which was strongly influenced by the energy input itself. On the other hand, a rising energy per unit length led to a decelerated cooling process. Even if the primary crystallization of the molten area was completed after the solidification interval had been passed, the secondary crystallization of the polymer
Fig. 6 Comparison of the temperature-time profile in the joining zone for $200 \mathrm{~kJ} \mathrm{~m}^{-1}$ and $400 \mathrm{~kJ} \mathrm{~m}^{-1}$

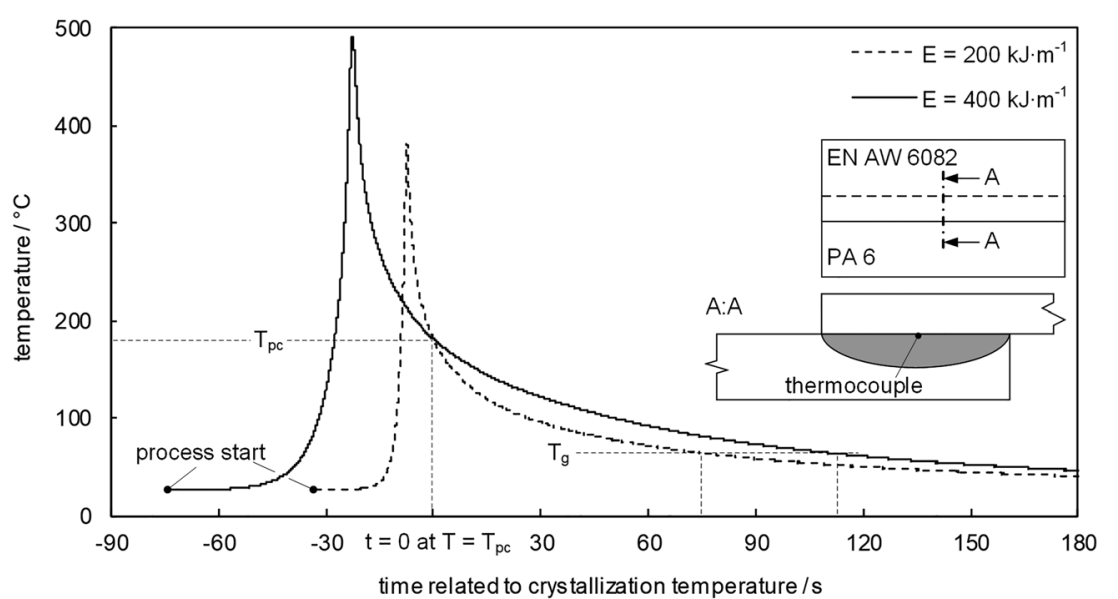


stopped when the temperature fell below glass transition temperature $\left(T_{\mathrm{g}}=63{ }^{\circ} \mathrm{C}\right.$, determined for a heating rate of $20 \mathrm{~K}$ $\min ^{-1}$ ). This was demonstrated as an example for the time interval between crystallization temperature $T_{\mathrm{pc}}$ and glass transition temperature $T_{\mathrm{g}}$ in Fig. 6. An increasing length of this time interval led to a further heat treatment of the polymer and was therefore expected for higher energies per unit length.

The effect of solidification conditions within the molten area was further examined by means of hardness tests. Figure 7 shows a comparative hardness curve between the minimum and maximum energy per unit length. The change in hardness is indicated on the ordinate compared with the base material for a better comparability, whose level was determined on the basis of five measurements and a maximum standard deviation of $\pm 0.17 \mathrm{HV} 0.01 / 60$. The zero point was placed at the direct boundary of the molten area to the base material on the abscissa. In the direction of base metal, the formation of a heat-affected zone was determined. This zone is extended further in the direction of the polymeric base material with increasing energy per unit length due to the longer time at higher temperatures in the joining process. The maximum achieved hardness deviation was similar in both cases considered. A slightly increased hardness level was determined for $400 \mathrm{~kJ} \mathrm{~m}^{-1}$ within the molten area compared to the base material, whereas a significantly reduced hardness level was achieved for $200 \mathrm{~kJ} \mathrm{~m}^{-1}$. The examinations made it clear that the energy per unit length can be utilized to influence the properties of the polymer. The hardness test did not provide any indication of the underlying mechanisms of the differing properties, e.g., degree of crystallization or crystal modification. Further experiments were therefore carried out.

In Fig. 8, diffractograms of the molten area for two examined energies per unit length are compared. The crystal modification was identified by characteristic peaks and appears comparable for $200 \mathrm{~kJ} \mathrm{~m}^{-1}$ and $400 \mathrm{~kJ} \mathrm{~m}^{-1}$. The $\alpha$ - modification was much more common than the gamma phase in the molten area; the presence of the latter was still detectable but at a low level This differs significantly from the results of spot joint tests that showed a pronounced increase of $\gamma$-modification within the molten area due to the higher cooling rate [8]. In contrast, the intensity of the peaks was increased at an energy per unit length of $400 \mathrm{~kJ} \mathrm{~m}^{-1}$ compared to $200 \mathrm{~kJ} \mathrm{~m}^{-1}$, indicating an increased degree of crystallization. The temperature measurements carried out (Fig. 6) suggest that the effect may have been caused by slower solidification and thus increased primary crystallization. On the other hand, secondary crystallization may have intensified due to the heat treatment in the cooling process until the glass transition temperature was reached. The observed increase in hardness could not therefore be explained by a change in the crystal modification but required a closer look at the degree of crystallization or primary and secondary crystallization.

A further characterization was carried out based on DSC analyses of thin sections taken from the molten area. An average degree of crystallization of $27.5 \%$ or $28.5 \%$ was determined for the line energies of $200 \mathrm{~kJ} \mathrm{~m}^{-1}$ and $400 \mathrm{~kJ} \mathrm{~m}^{-1}$. A clear influence of energy per unit length on degree of crystallization was not found due to the small difference in the mean value and the associated standard deviation of approx. $\pm 1 \%$. A comparison of DSC curves between the energies per unit length provides further insights (Fig. 9). The DSC curves show two peaks: a main peak at approx. $220^{\circ} \mathrm{C}$ and an initial peak at approx. $207-209^{\circ} \mathrm{C}$. A slight shift in peak temperature, approx. $+0.5 \mathrm{~K}$, occurred in the main peak as a result of the increase in energy per unit length from 200 to $400 \mathrm{~kJ} \mathrm{~m}^{-1}$. This may reflect a slight increase in crystal lamellae thickness or spherulite size as discussed above in the context of morphology (Fig. 5). The occurrence of the first peak may indicate the presence of $\gamma$-modification, but it may also be influenced by secondary crystallization $[21,25]$. A comparison with
Fig. 7 Characteristic curve of the hardness level at different energies per unit length

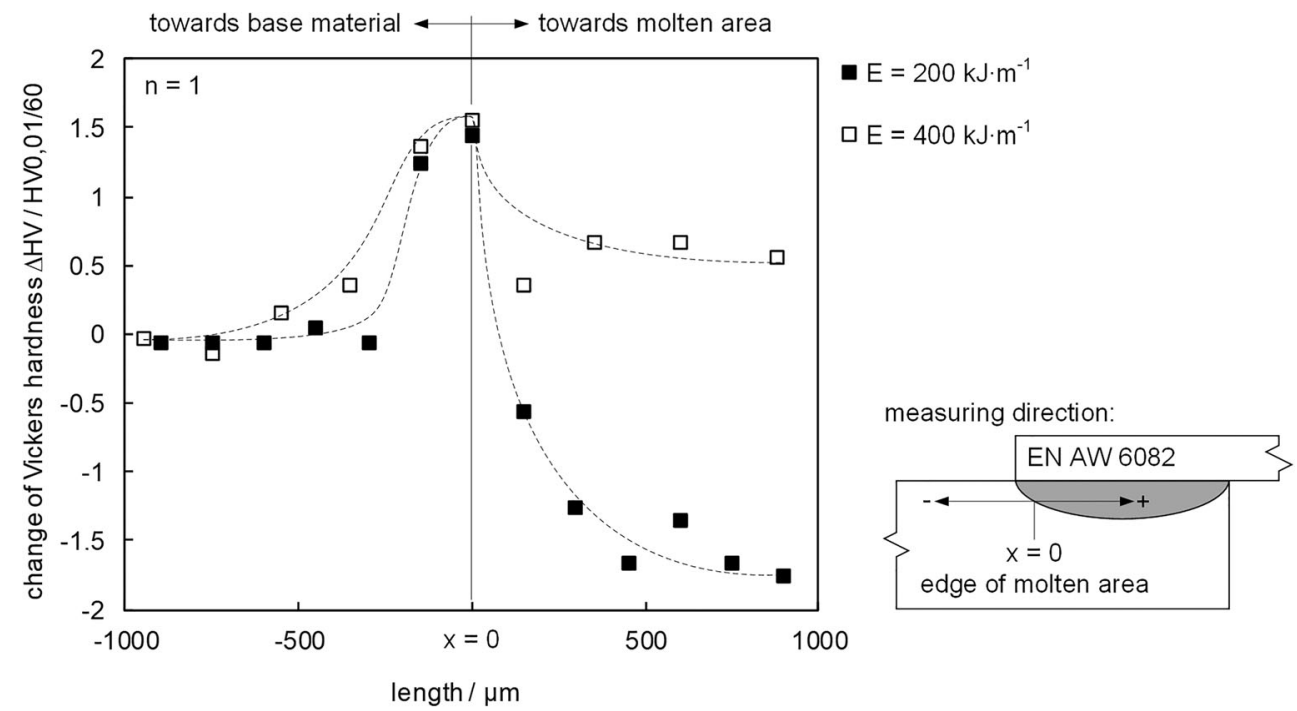


Fig. 8 Characterization of crystal modifications of PA 6 in the molten area as a function of the energy per unit length by X-ray diffraction

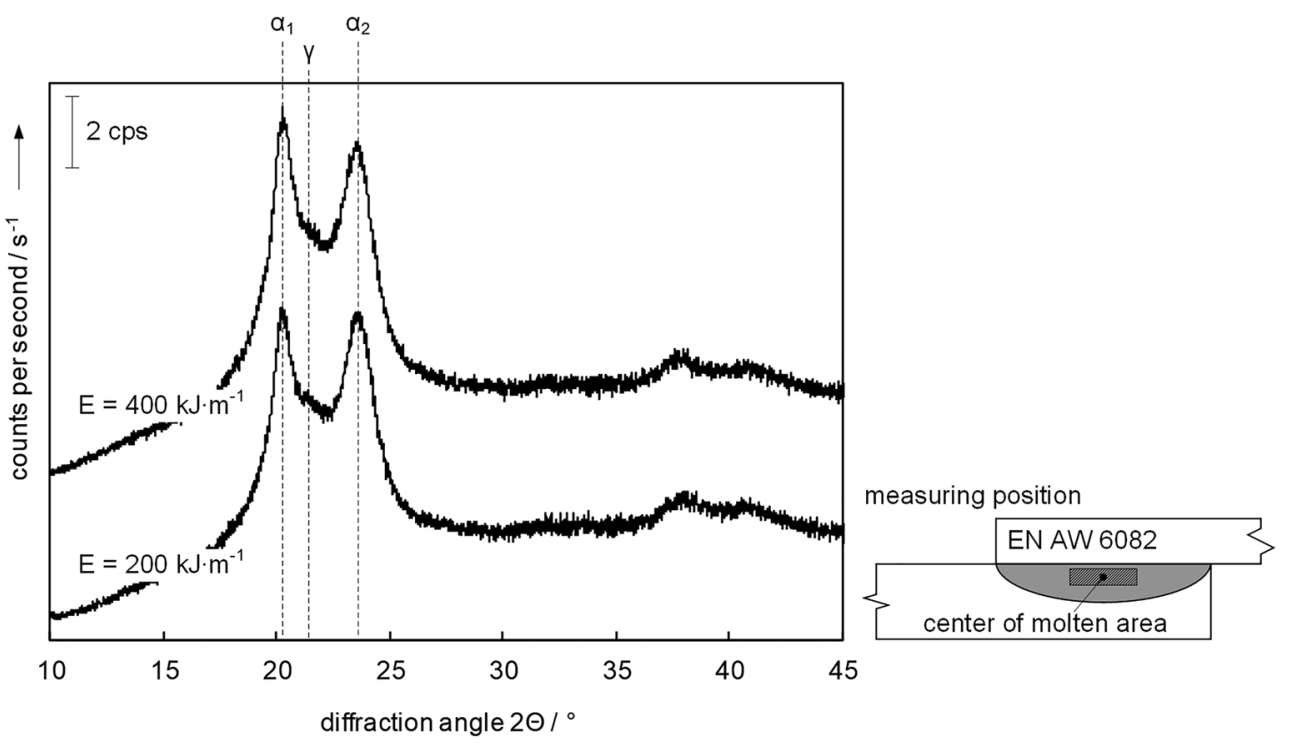

$400 \mathrm{~kJ} \mathrm{~m}^{-1}$ shows that the first peak is more pronounced; i.e., the slope is much steeper and at the same time, the peak temperature shifts from 209.3 to $207.0^{\circ} \mathrm{C}$. Since the XRD analyses showed no significant change in the proportion of $\gamma$-modification, the change in the peak is therefore attributed to secondary crystallization. This was verified by means of reference tests applying a heat treatment after joining for samples joined at an energy per unit length of $200 \mathrm{~kJ} \mathrm{~m}^{-1}$ (temperature: $160{ }^{\circ} \mathrm{C}$, time: $20 \mathrm{~min}$ ). The result clarifies that the expression of the first peak can be adjusted accordingly by heat treatment to the results of $400 \mathrm{~kJ} \mathrm{~m}^{-1}$. It can be stated that the heat treatment during the cooling phase has a significant influence on the properties and morphology of the polymer.

The trials showed an effect of the energy per unit length on the properties of the polymer in the molten area by adjusting crystallization, thermoplastic morphology, and heat-affected zone in the base material. The effect on mechanical properties of hybrid metal-polymer composites can be examined in more detail.

\subsection{Mechanical properties in short-term testing}

A cohesive failure of the weaker joining partner is addressed regarding the industrial application so that the joint is ideally determined by the base material properties. Non-reinforced polymers fail cohesively in mechanical testing because an adequate surface treatment and bonding surface was present for the described joint configuration and process setup. The mechanical behavior in the short-term test was examined by means of tensile-shear tests for metal-polymer samples. The properties of the chosen parameters were characterized in Sections 3.1 and 3.2 as a function of energy per unit length. The specification of a strength was deliberately omitted due to cohesive failure in the polymer.

The tensile-shear forces and crosshead displacements are given in Fig. 10 for different energies per unit length. A tensile-shear force of $7944 \mathrm{~N} \pm 92 \mathrm{~N}$ was achieved for $200 \mathrm{~kJ} \mathrm{~m}^{-1}$ compared to $6333 \mathrm{~N} \pm 1060 \mathrm{~N}$ for $400 \mathrm{~kJ} \mathrm{~m}^{-1}$. The lower energy per unit length led to higher forces with significantly reduced standard deviations. The higher forces
Fig. 9 DSC analysis of the molten area for the energies per unit length $400 \mathrm{~kJ} \mathrm{~m}^{-1}, 200 \mathrm{~kJ}$ $\mathrm{m}^{-1}$, and $200 \mathrm{~kJ} \mathrm{~m}^{-1}$ after heat treatment at $160{ }^{\circ} \mathrm{C}$ for $20 \mathrm{~min}$

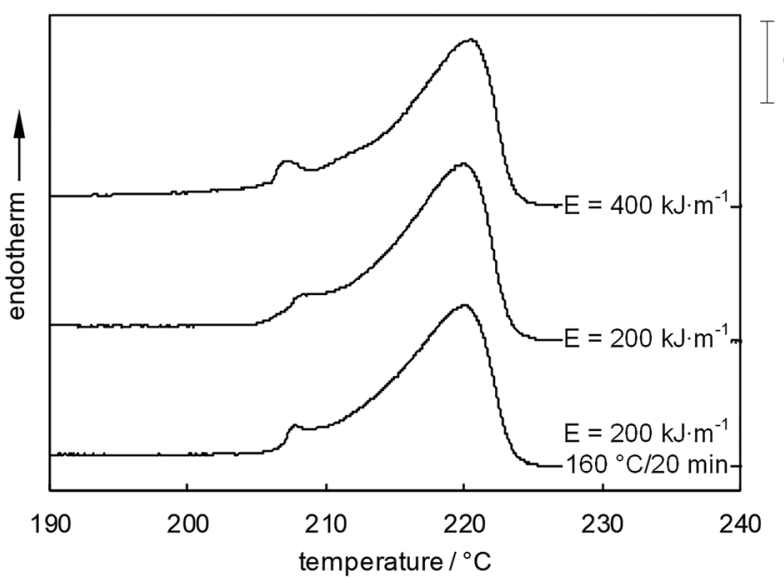
$0,5 \mathrm{~mW} \cdot \mathrm{mg}^{-1}$

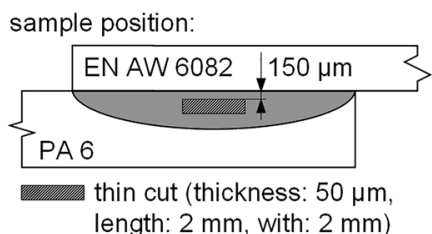


Fig. 10 Short-term testing for different energies per unit length and heat treatments for affecting the secondary crystallization

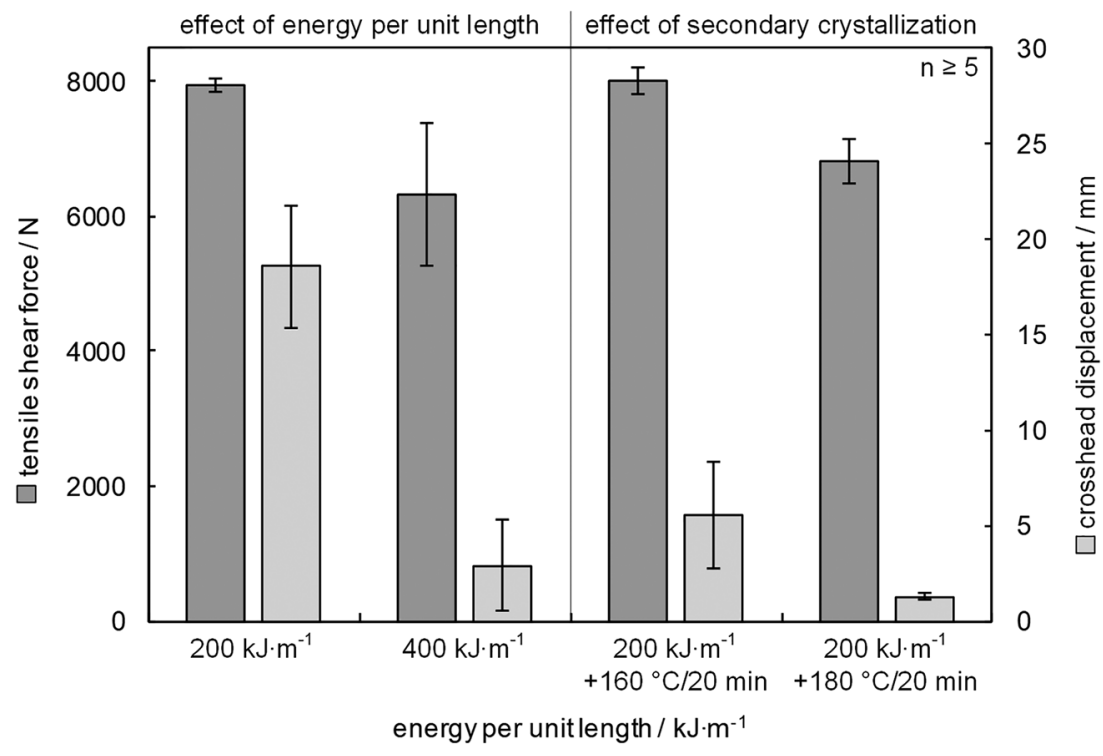

can be partially attributed to the load-bearing cross-section of the PA 6, since the metallic joining partner penetrated further into the polymer during the joining process with increasing energy per unit length (Section 3.1). The polymeric crosssection was reduced $5 \%$ at $400 \mathrm{~kJ} \mathrm{~m}^{-1}$ compared to $200 \mathrm{~kJ}$ $\mathrm{m}^{-1}$, which is why the reduction in tensile-shear force of approx. $20 \%$ cannot only be attributed to this factor. The traverse paths, which provide an indication of the ductility of the composite, reduced from 18.6 to $2.9 \mathrm{~mm}$.

In order to understand the possible influence of secondary crystallization on the mechanical properties, as demonstrated in Section 3.2, further experiments were carried out for tensile-shear samples at an energy per unit length of $200 \mathrm{~kJ}$ $\mathrm{m}^{-1}$. These were heat-treated at elevated temperatures $\left(160^{\circ} \mathrm{C}\right.$ and $180{ }^{\circ} \mathrm{C}$ for $20 \mathrm{~min}$ each). The reference trials on heattreated specimens did not fully reflect the material processes within the joining process, as other temperature-time profiles occurred during the cooling process but allowed the fundamental traceability of the effects induced by secondary crystallization. Secondary crystallization was accelerated with increasing temperatures; i.e. further amorphous areas can crystallize. The occurrence of a renewed phase transformation was neglected due to the predominantly present and stable $\alpha$ modification [20, 25].

The tensile-shear forces achieved/reached/attained in this study and the crosshead displacements were significantly influenced by secondary crystallization compared to the initial state (Fig. 10). A significant reduction of the crosshead displacement from 18.6 to $5.5 \mathrm{~mm}$ occurred for a heat treatment at $160{ }^{\circ} \mathrm{C}$, while the average tensile-shear force reaches a constant level with a slightly increased standard deviation. the tensile-shear force drops to approx. $6826 \mathrm{~N} \pm 335 \mathrm{~N}$ and the crosshead displacement drops simultaneously to $1.26 \mathrm{~mm}$ $\pm 0.2 \mathrm{~mm}$ for heat-treated samples at $180{ }^{\circ} \mathrm{C}$. The crosshead displacement and the tensile-shear force are therefore in a comparable range to the energy per unit length of $400 \mathrm{~kJ}$ $\mathrm{m}^{-1}$. The effect of different superstructure sizes or the notch effect at the edge of the overlap between the different energies per unit length was only of minor importance for the mechanical properties. In contrast, the mobility of the amorphous regions was/is strongly restricted by the secondary crystallization that led to a massive reduction of the traverse path.

Characteristic force-crosshead displacement graphs from tensile-shear testing illustrate this effect by means of different energies per unit length and heat treatment conditions (Fig. 11). The slope of the curves was comparable up to a force of approx. $6000 \mathrm{~N}$ and a reached crosshead displacement of approx. $1.2 \mathrm{~mm}$ (Fig. 11, detailed section Z). The ultimate stress was reached at $400 \mathrm{~kJ} \mathrm{~m}^{-1}$ (1) and an abrupt failure of the joint occurred. Tensile-shear force continued to increase for the lowest energy per unit length of $200 \mathrm{~kJ} \mathrm{~m}^{-1}$ (2) until the yield stress was reached at approx. $8000 \mathrm{~N}$ and necking started. Tensile-shear force declined until the specimen fractured; the cross-section of the polymer decreased significantly during this time and correspondingly high stresses were present within the neck. The overall composite showed a significantly higher ductility than the maximum considered energy per unit length. This behavior was primarily attributed to secondary crystallization as already explained, which can also be discerned in the force-crosshead displacement curves on the basis of heat-treated samples. The samples were produced with an energy per unit length of $200 \mathrm{~kJ} \mathrm{~m}^{-1}$ and stored at $160{ }^{\circ} \mathrm{C} \mathrm{(3)} \mathrm{and} 180{ }^{\circ} \mathrm{C}$ (4) for $20 \mathrm{~min}$. The failure behavior was significantly influenced by this heat treatment and resulted in a shift from a ductile fracture (2) to a brittle fracture (4) with an otherwise geometrically unaltered joining zone.

Failure behavior of the composite remained cohesive and the failure location was within the thermoplastic material in all 
Fig. 11 Characteristic forcecrosshead displacement graphs for different energies per unit length and heat treatments

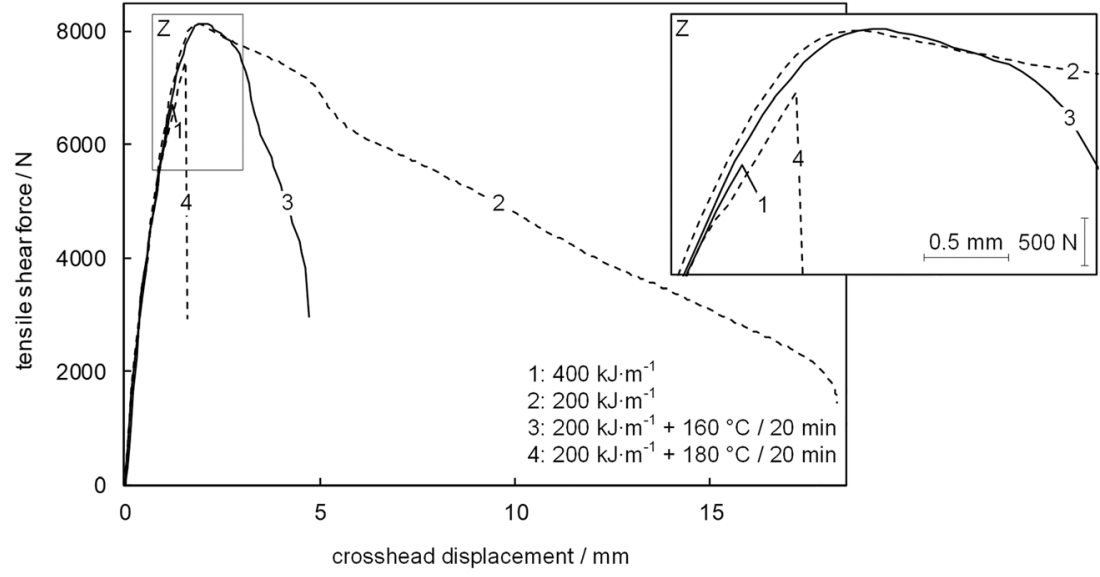

cases considered. Figure 12 shows the fracture using materialographic micrographs and images of the fracture surface using selected specimens. The necking occurred at the transition from the overlap area to the thermoplastic base material due to the local stress concentration for $200 \mathrm{~kJ} \mathrm{~m}^{-1}$ (a). The deformation was visible until melt ejection. At this point, the properties of the base material were decisive for the failure behavior and thus also for the high ductility of the overall composite. The fracture surface was characterized by high elongation and recognizable white fracture. The composite failed significantly less ductile for high energies per unit length, sometimes forming a completely brittle fracture surface (b). The brittle fracture surface was not always as distinctive as in the example shown (b), but was favored by increasing secondary crystallization. The brittle behavior occurred

a)
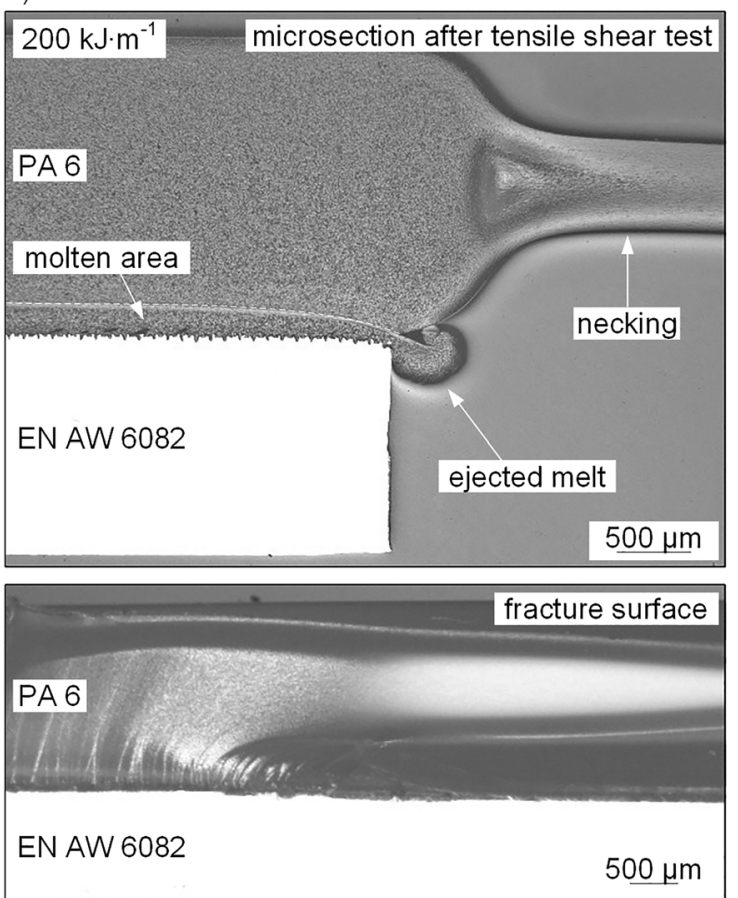

accordingly more frequently $\left(160{ }^{\circ} \mathrm{C} / 20 \mathrm{~min}\right)$ or exclusively $\left(180{ }^{\circ} \mathrm{C} / 20 \mathrm{~min}\right)$ for heat-treated samples. The formation of the crack always led to an abrupt failure in the shear tensile test.

Crack initiation can also be traced back to the transition between lap joint and base material at $400 \mathrm{~kJ} \mathrm{~m}^{-1}$ due to the stress distribution. The exact point of origin within the polymer was uncertain, e.g. whether it was initiated within the molten area or the heat-affected zone. Crack formation was assumed to occur in the area of the largest secondary crystallization due to the effect of the heat treatment, i.e. within the molten area. It should be noted from an engineering point of view that the failure behavior can be specifically affected or adjusted by process management.

b)

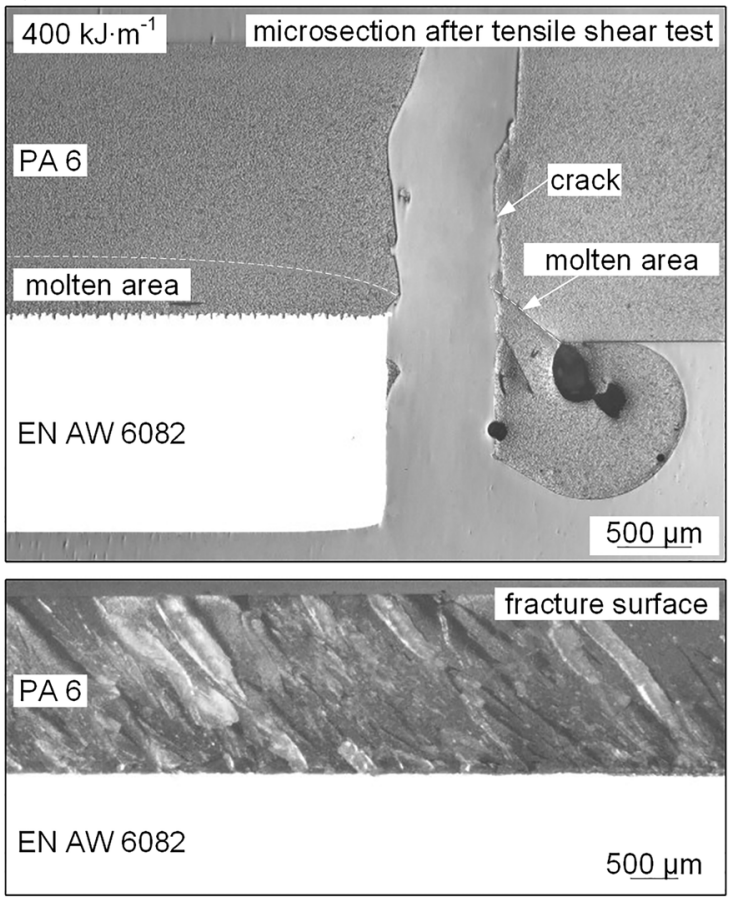

Fig. 12 Comparison of failure behavior based on microsections and fracture surfaces after tensile-shear test for a $200 \mathrm{~kJ} \mathrm{~m}^{-1}$ and b $400 \mathrm{~kJ} \mathrm{~m}$ 


\subsection{Mechanical properties in fatigue testing}

Mechanical behavior in fatigue testing was also examined in addition to the effect of the energy per unit length on the properties during short-term testing. The fatigue behavior for a cyclically oscillating tensile-shear load was determined ( $R=0.1$, see Section 2 ) based on a comparable load profile. 10 million cycles were achieved for all specimens $(n=3)$ for an energy per unit length of $200 \mathrm{~kJ}$ $\mathrm{m}^{-1}$, whereas for $400 \mathrm{~kJ} \mathrm{~m}^{-1}$, an average cycle number of 1.13 million was reached. A very high deviation was therefore obtained (minimum cycle number: 196,000, maximum cycle number achieved: 2.36 million, $n=3$ ). The fracture was associated with a cohesive failure of the thermoplastic joining partner in all cases of $400 \mathrm{~kJ} \mathrm{~m}^{-1}$. No damage to the specimen was detected for $200 \mathrm{~kJ} \mathrm{~m}^{-1}$. This behavior illustrates the influence of the energy at length on the mechanical properties beyond the shortterm testing.

The evaluation of the resonant frequency over the number of cycles provided a deeper understanding of the damage to the specimens. The frequency drop also enabled the detection of cracks. Figure 13 a compares the resonant frequency curve for 200 and $400 \mathrm{~kJ} \mathrm{~m}^{-1}$. The resonant frequency at the beginning of the test was $43.3 \mathrm{~Hz}$ and comparable for both samples. An almost constant frequency curve occurred for $400 \mathrm{~kJ} \mathrm{~m}^{-1}$ over the number of cycles until a crack was formed at approx. 2.3 million cycles and the associated frequency dropped abruptly.

In contrast, the resonant frequency decreased gradually with increasing number of cycles for $200 \mathrm{~kJ} \mathrm{~m}^{-1}$, from/ regarding which a material side-effect can be assumed/inferred. This behavior is explained by the greater mobility of the amorphous chain segments within the polymer at $200 \mathrm{~kJ}$ $\mathrm{m}^{-1}$ compared to $400 \mathrm{~kJ} \mathrm{~m}^{-1}$. The resonant frequency dropped by $0.8 \mathrm{~Hz}$ over 10 million cycles in the course of the entire test. No damage to the material was detected in the visual inspection and no cracks were detected in the materialographic analysis (Fig. 13b). Macroscopic damage to the composite can be ruled out at this point; further studies using scanning electron microscopy could more detailed information on possible pre-damage as a function of the number of load cycles.

The maximum energy per unit length of $400 \mathrm{~kJ} \mathrm{~m}^{-1}$ showed an obvious crack. The crack occurred in the range of the maximum stress at the edge of the lap joint as in the short-term test. The crack propagated in the direction of the upper surface, but crack initiation cannot be precisely
Fig. 13 Resonant frequency over a number of cycles for $200 \mathrm{~kJ} \mathrm{~m}^{-1}$ and $400 \mathrm{~kJ} \mathrm{~m}^{-1}$ (a) and materialographic images of crack propagation (b)

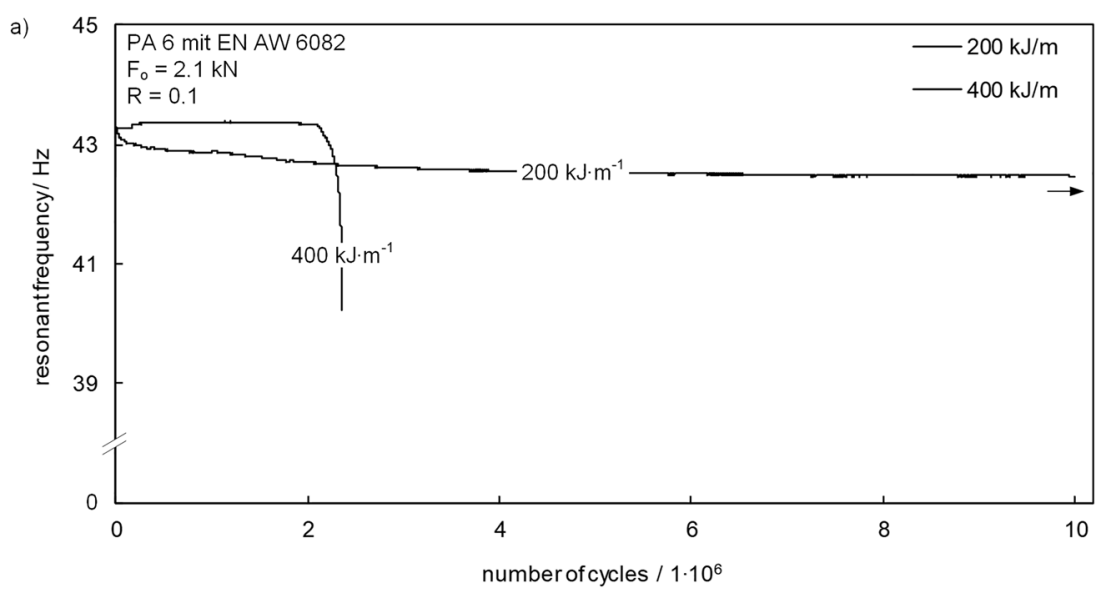

b)
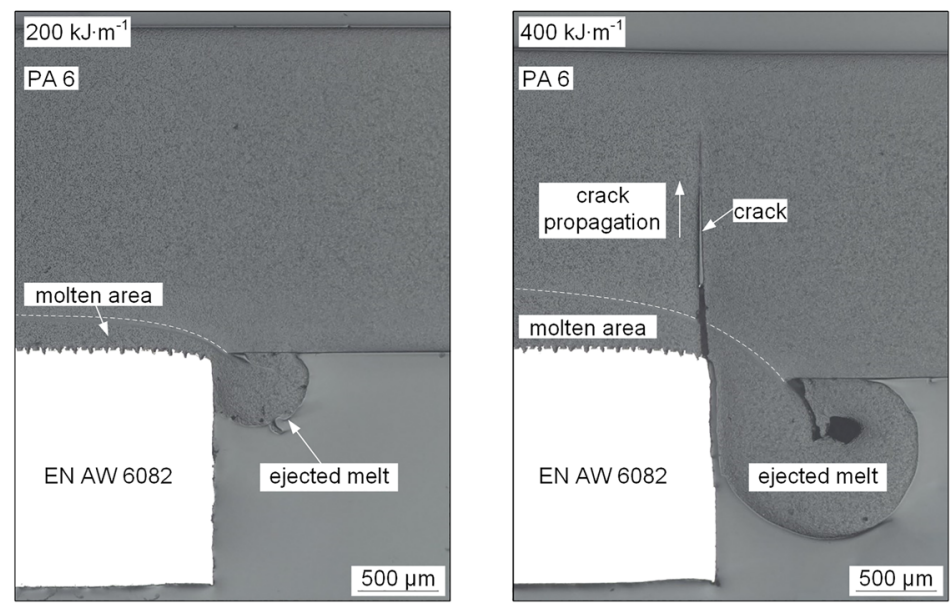
determined, i.e. whether the crack started in the heataffected zone or the molten area. It should be noted that the energy per unit length significantly influences the thermoplastic material and the fatigue behavior of the hybrid structure from an engineering point of view, even in the case of cohesive failure.

\section{Conclusion}

Process management enables properties of the joining zone to be adjusted on the basis of energy per unit length and thus influences the mechanical properties of the metal-polymer joint. Cohesive failure was positively influenced by the reduction of the energy per unit length regarding an increase of crosshead displacement in the short-term test and a significantly improved fatigue behavior for an overlap width of 16 $\mathrm{mm}$.

Secondary crystallization of the polymer was determined as a decisive factor and referenced by heat-treated specimens based on DSC and XRD analyses. A subordinate influence of the size of the molten area, the notch effect due to melt ejection, the load-bearing cross-section of the thermoplastic, and size or shape of superstructures between the considered line energies could be determined.

From this, it can be concluded that addressing low energies per unit length leads to advantageous properties of metalpolymer joints and that high joining speeds, in addition to economic benefits, can also offer technological advantages for the application of hybrid composites.

Acknowledgments Open Access funding enabled and organized by Projekt DEAL. The authors would like to thank the Institute of Microand Nanotechnologies MacroNano ${ }^{\circledR}$ at the Technische Universität Ilmenau and James Lenard for proof-reading the paper.

Open Access This article is licensed under a Creative Commons Attribution 4.0 International License, which permits use, sharing, adaptation, distribution and reproduction in any medium or format, as long as you give appropriate credit to the original author(s) and the source, provide a link to the Creative Commons licence, and indicate if changes were made. The images or other third party material in this article are included in the article's Creative Commons licence, unless indicated otherwise in a credit line to the material. If material is not included in the article's Creative Commons licence and your intended use is not permitted by statutory regulation or exceeds the permitted use, you will need to obtain permission directly from the copyright holder. To view a copy of this licence, visit http://creativecommons.org/licenses/by/4.0/.

\section{References}

1. Balle F, Emrich S, Wagner G, Eifler D, Brodyanski A, Kopnarski M (2013) Improvement of ultrasonically welded aluminum/carbon fiber reinforced polymer-joints by surface technology and high resolution analysis. Adv Eng Mater 15(Nr. 9):814-819
2. Mitschang P, Velthuis R, Didi M (2013) Induction spot welding of metal/CFRPC hybrid joints. Adv Eng Mater 15(Nr. 9):804-813

3. Georgiev GL, Baird RJ, Newaz G, Auner G, Witte R, Herfurth H (2004) An XPS study of laser-fabricated polyimide/titanium interfaces. Appl Surf Sci 236:71-76

4. Niwa Y, Kawahito Y, Kubota S, Katayama S (2008) Evolution of LAMP joining to dissimilar metal welding, ICALEO 2008 Congress Proceedings, Paper \#606, 311-317

5. Schricker K, Bergmann JP (2018) Determination of sensitivity and thermal efficiency in laser assisted metal-plastic joining by numerical simulation. Proced CIRP 74:518-523

6. Schricker K, Stambke M, Bergmann JP (2014) Experimental investigations and modelling of the melting layer in polymer-metal hybrid structures. Weld World 59:407-412

7. Schricker K, Bergmann JP (2019) Temperature- and timedependent penetration of surface structures in thermal joining of plastics to metals. Key Eng Mater 809:378-385

8. Schricker K, Bergmann JP, Hopfeld M, Spieß L (2018) Characterization of the joining zone in laser direct joining between thermoplastics and metals. In: Proceedings of Hybrid Materials and Structures 2018, Bremen 6 p

9. Schricker K, Stambke M, Bergmann JP, Bräutigam K (2016) Laserbased joining of thermoplastics with metals: influence of varied ambient conditions on joint performance and microstructure. Int $\mathrm{J}$ Polym Sci 9:5301081

10. Goushegir SM (2015). Friction spot joining of metal-composite hybrid structures, Helmholtz-Zentrum Geesthacht, Zentrum für Material- und Küstenforschung, HZG REPORT 2015-5, PhD thesis

11. Mitschang P, Velthuis R, Emrich S, Kopnarski M (2009) Induction heated joining of aluminum and carbon fiber reinforced nylon $66 . \mathrm{J}$ Thermoplast Compos Mater 22:767-801

12. Velthuis R (2007). Induction welding of fiber reinforced thermoplastic polymer composites to metals, IVW-Schriftenreihe 75, Institut für Verbundwerkstoffe $\mathrm{GmbH}$, Kaiserslautern, $\mathrm{PhD}$ thesis

13. Egen U (1985). Gefügestruktur in Heizelementschweißnähten an Polypropylen-Rohren, Schweißtechnische Forschungsberichte 4, Deutscher Verlag für Schweißtechnik (DVS) GmbH Düsseldorf, $\mathrm{PhD}$ thesis, University Kassel

14. Gehde M (1993). Zum Extrusionsschweißen von Polypropylen, University Erlangen-Nürnberg, $\mathrm{PhD}$ thesis

15. Michel P (1999) Schweißverfahren in der Kunststoffverarbeitung. Grundlagen und Aspekte zur Serienfertigung, DVS-Berichte Band 203, DVS-Verlag GmbH Düsseldorf, University Paderbor

16. Starkweather HW, Brooks RE (1959) Effect of spherulites on the mechanical properties of nylon 66. J Appl Polym Sci 1(2):236-239

17. Jabbari-Farouji S, Rottler J, Lame O, Makke A, Perez M, Barrat J-L (2015) Plastic deformation mechanisms of semicrystalline and amorphous polymers. ACS Macro Lett 48(1):2-18

18. Struik LCE (1977). Physical aging in amorphous polymers and other materials, Technische Hochschule Delft, $\mathrm{PhD}$ thesis

19. Hay IL, Keller A (1965) Polymer deformation in terms of spherulites. Colloid Polym Sci 204(Nr. 1/2):43-74

20. Kyotani M, Mitsuhashi S (1972) Studies on crystalline forms of Nylon 6. II. Crystallization from the Melt. J Polym Sci Part A-2 10:1497-1508

21. Murthy NS, Aharoni SM, Szollosi AB (1985) Stability of the $\gamma$ form and the development of the $\alpha$ form in nylon 6. J Polym Sci Polym Phys Ed 23:2549-2565

22. Dasgupta S, Hammond WB, Goddard WA (1996) Crystal structures and properties of nylon polymers from theory. J Am Chem Soc 118:12291-12301

23. Itoh T, Miyaji H, Asai K (1975) Thermal properties of $\alpha$ - and $\gamma$ form of nylon 6. Jpn J Appl Phys 14(Nr. 2):206-215 
24. Murthy NS, Kagan VA, Bray RG (2002) Effect of melt temperature and skin-core morphology on the mechanical performance of nylon 6. Polym Eng Sci 42(Nr. 5):940-950

25. Shan G-F, Yang W, Tang X-E, Yang M-B, Xie B-H, Fu Q, Mai YW (2010) Multiple melting behaviour of annealed crystalline polymers. Polym Test 29:273-280

26. Amend P, Mohr C, Roth S (2014) Experimental investigations of thermal joining of polyamide aluminium hybrids using a combination of mono- and polychromatic radiation. Phys Procedia 56:824834

27. Lambiase F, Genna S (2017) Laser-assisted direct joining of AISI304 stainless steel with polycarbonate sheets: thermal analysis, mechanical characterization, and bonds morphology. Opt Laser Technol 88:206-214

28. Heckert A, Zaeh MF (2015) laser surface pre-treatment of aluminium for hybrid joints with glass fibre reinforced thermoplastics. J Laser Applic 27:Nr. S2
29. Balle F, Wagner G, Eifler D (2007) Ultrasonic spot welding of aluminum sheet/carbon fiber reinforced polymer-joints. Mater Werkst 38(Nr. 11):934-938

30. Wahba M, Kawahito Y, Katayama S (2011) Laser direct joining of AZ91D thixomolded Mg alloy and amorphous polyethylene terephthalate. J Mater Process Technol 211:1166-1174

31. Sun X, Stephens EV, Davies RW, Khaleel MA, Spinella DJ (2004) Resistance spot welding of aluminum alloy to steel with transition material - from process to performance - part i: experimental study. Weld J 2004:188-195

32. Schricker K, Diller S, Bergmann JP (2018) Bubble formation in thermal joining of plastics with metals. Proced CIRP 74:518-523

Publisher's note Springer Nature remains neutral with regard to jurisdictional claims in published maps and institutional affiliations. 